\title{
Where are the female experts? Perceptions about the absence of female presenters at a Digital Health Conference in Bolivia
}

\author{
Sarah Sullivan, Ana Posada, Matthew Hawkins, Giomar Higueras \\ Touro University California, Mare Island, Vallejo, CA, USA \\ Contributions: (I) Conception and design: All authors; (II) Administrative support: G Higueras; (III) Provision of study materials or patients: A \\ Posada, M Hawkins; (IV) Collection and assembly of data: G Higueras; (V) Data analysis and interpretation: All authors; (VI) Manuscript writing: All \\ authors; (VII) Final approval of manuscript: All authors. \\ Correspondence to: Sarah Sullivan. Touro University California, 1310 Club Drive, Mare Island, Vallejo, CA 94592, USA. Email: Sarah.sullivan@tu.edu.
}

Background: Gender disparities exist worldwide related to female representation in digital health initiatives especially in low and middle income countries (LMICs). Upstream approaches and policy implementation has been effective in some countries to reduce the gender gap in the areas of political and sector leadership. At an international digital health conference in Bolivia, all-male expert panels presented their research and innovations to audiences from the Bolivian national and regional health departments and private and non-governmental organization heath leaders.

Methods: An in-depth qualitative analysis of participant perspectives related to the absence of female presenters at this digital health conference in Bolivia was performed. Using a cross-sectional research design, the questionnaire rated the respondents' satisfaction using Likert scales and their perspectives using openended questions. A multidisciplinary team of coders reviewed the respondents' responses in detail and developed general themes.

Results: The sample consisted of 80 respondents who completed the questionnaire from the 115 people attending the conference, giving a $70 \%$ response rate (80/115). Respondents were broadly represented in terms of gender, age, occupation and experience using digital health tools. The code structure contained five primary codes each reflecting sets of ideas and possible solutions for gender equality in science and health technology in Bolivia. The five recurrent themes, ranked from the most common mentioned to the least common, were: (I) opportunities and incentives (38\%); (II) indifference (23\%); (III) role models (18\%); (IV) capacity strengthening and empowerment (15\%); (V) norms and policies (7\%).

Conclusions: The results of this study can be useful for preparing a more representative digital health field in Bolivia overtime. Conference respondents provide key recommendations to reduce gender inequality at digital health conferences and in the field. This study provides evidence from Bolivian health workers and officials on their perspectives related to the absence of female presenters at an international digital health conference and their suggestions for optimizing female participation and leadership at conferences and in the digital health field going forward.

Keywords: Digital health; gender gap; scientific conference panels; Bolivia

Received: 17 February 2020; Accepted: 22 May 2020; Published: 05 October 2020.

doi: 10.21037/mhealth-2019-di-12

View this article at: http://dx.doi.org/10.21037/mhealth-2019-di-12 


\section{Introduction}

Gender inequality is an unfortunate reality in most countries and regions. International covenants, such as the Convention on the Elimination of All Forms of Discrimination against Women, call to end discrimination and suggest processes to facilitate change to achieve gender equality. The United Nation's Sustainable Development Goals (SDGs) prioritize the need for gender equality and provide a blueprint for nations to empower women and girls (1). Gender equality is a fundamental theme within the SDGs and this cross cutting goal must be met before many of the other goals can be reached. The need for women researchers within the science, technology, engineering, mathematics, medicine and innovation (STEMMI) ecosystem is highlighted in regional strategies and documents (2). Addressing gender gaps in political and leadership roles is critical for progress (3). Women make up only $24.5 \%$ of parliamentary seats globally (women in parliaments: world and regional averages, s. f.) and $5 \%$ of the world's Fortune 500 CEOs (4).

Within emerging areas of global development such as digital health initiatives, a disparity between male and female representation exists worldwide, but there is little evidence about perspectives on gender gaps in health technology especially in low and middle income countries (LMICs) (5). There is new attention to policies in developing countries to address women's participation in political, economic and public life (6). In Bolivia, the implementation of the 2013 policy on Gender Parity in Electoral Bodies resulted in a steady increase in the proportion of women in political leadership roles (7). The percentage of females in Bolivia's national parliaments rose from $16.9 \%$ in 2007 to $53.1 \%$ in 2017 (8). Bolivia is also one of the few countries in the Pan American Health Organization (PAHO) region led by two female health ministers during recent years [2015-2019]. Women are now leaders in many sectors, but in the area of digital health innovations, the gender gap is still significant especially in LMICs (9). Understanding the impact of this digital health gender gap in the field and identifying possible solutions can be a first step.

At a national digital health conference in Bolivia in 2019, there were 15 expert presenters who were all men. This study describes participant perceptions and suggestions related to the absence of female presenters at the Digital Health conference in La Paz, Bolivia. We present the following article in accordance with the STROBE reporting checklist (available at http://dx.doi.org/10.21037/mhealth- 2019-di-12).

\section{Methods}

\section{Setting}

In 2018, the Bolivian government secured a World Bank loan to improve their Health Service Delivery Network. Included in the Procurement Plan were funds for a new National Health Information System and Hospital Management Information Systems (10). Rolling out the new health information system was a key goal of the health ministry. A digital transformation of the health system will require a broad participation of many actors (11). In May, 2019 the Bolivian Ministry of Health (MoH), InterAmerican Development Bank (IDB), and PROCOSI, a network of non-governmental organizations (NGOs), hosted a two day conference on the $\mathrm{MoH}$ technical health strategy, health information systems and digital health interventions to support the introduction and roll out of a new health information system across Bolivia.

The digital health conference goals were to disseminate, socialize, and build capacity, coordination and networking for digital health interventions in Bolivia. International, regional and national experts were invited to present at the conference on their advances using digital health interventions for clients, health workers, health system managers and data services (12). The keynote addresses from the Director of the Health Information Department laid out the government's strategic health technology plan and new health information systems. International experts also presented and debated on mobile health (mhealth), electronic medical records, facility management systems, telemedicine and data exchange during the event. Although the conference organizers tried to locate and invite women to participate on the expert panels, they were not successful. During the two-day conference, fifteen men presented their digital health innovations, systems and interventions to the audience.

\section{Instrument}

A framework adapted from the NEVES methodology was used to evaluate the conference (13). Evaluation questions were adapted from the NEVES instrument and revised to align with the Digital Health conference objectives. The survey themes and questions were further developed collaboratively with bilingual study team members. 
Questions were translated from English to Spanish and Spanish to English, piloted and revised. The questionnaire was piloted by two members of the research team through cognitive interviewing with five participants. The pilot participants included 3 doctors working in the public health sector and two directors of public health NGOs. Piloting was done utilizing think aloud and verbal probing techniques. Based on the piloting process, revisions were made to the questionnaire in the introduction and demographic categories sections. The pilot participants felt that the questionnaire was easy to read and didn't take too long to complete.

The final fifteen-item questionnaire was designed to rate the respondents' satisfaction using Likert scales and their perspectives using open-ended questions. The questionnaire domains included demographics, conference logistics, conference impact and general feedback about the conference. The questionnaire measured the respondents' knowledge about digital health, intent to utilize digital health interventions, potential benefits and challenges of digital health interventions, and digital health policies.

\section{Sampling and recruitment}

At the end of the final conference session, a PROCOSI member approached each of the conference tables and distributed the evaluation questionnaire to all the participants to complete. She collected their completed questionnaire as they exited the conference.

\section{Ethics}

The Touro University California Institutional Review Board (IRB) as well as the Universidad Mayor de San Simon Bioethics Committee approved this evaluation study. The informed consent was explained in the introduction of the questionnaire.

\section{Analysis}

The answers to the demographic questions were entered into an excel spreadsheet and analyzed quantitatively to obtain means and proportions. The open-ended question reviewed for this study was; The organizers were not able to obtain the participation of female presenters for the conference. What is your reaction about this issue and what do you propose to increase the presence and participation of women in the Digital
Heath field in Bolivia? The answers to this open-ended question were compiled and analyzed qualitatively. Using a grounded theory inductive strategy, a multidisciplinary team of coders reviewed the respondents' responses in detail and developed general themes. The themes were grouped using highlighted colors in the data base. The two main coders (one NGO leader from Bolivia and one Associate Professor from USA) both had experience with qualitative research and were well versed in the topic of gender equality. Two other junior colleagues, who had worked on the questionnaire development, were also invited to review the themes. In stages, the coders unified similar concepts and themes and ended with five primary codes in the final code structure.

\section{Results}

\section{Demographics}

Our final sample (Table 1) consisted of 80 respondents who completed the questionnaire from the 115 people attending the conference, giving a $70 \%$ response rate (80/115). Of these 80 respondents, 71 answered the open-ended question about women in digital health which yielded an $89 \%$ response rate $(71 / 80)$ to the question of interest for this study. Respondents were broadly represented in terms of gender, age, occupation and experience using digital health tools. Respondents were $31 \%$ female. The median age of all respondents was 44 years, $24 \%$ worked for the national or regional Ministry of Health, $16 \%$ worked in NGO management/coordination, $12 \%$ were health consultants and $8 \%$ were health workers at private/NGO hospitals and clinics. The respondents had varying levels of experience using digital health tools; with $22 \%$ reporting $1-5$ years of experience, $12 \%$ with $5-10$ years of experience, $11 \%$ with more than 10 years of experience, $10 \%$ with 6 months to a year and $7 \%$ with less than 6 months of experience using digital health tools. There were 23 respondents or $18 \%$ who had never used digital health tools before attending the conference. Participants at the conference were invited from all nine departments (states) in Bolivia.

\section{Themes}

Our final code structure (Table 2) contained five primary codes each reflecting sets of ideas and possible solutions for gender equality in science and health technology in Bolivia. 
Table 1 Characteristics of study participants

\begin{tabular}{|c|c|}
\hline Characteristic & Result* \\
\hline Median age (range), years & 44 [20-79] \\
\hline Female & $31[39]$ \\
\hline \multicolumn{2}{|l|}{ Occupation } \\
\hline $\begin{array}{l}\text { National/departmental (state) government } \\
\text { institution health official }\end{array}$ & $24[30]$ \\
\hline Professor & $3[4]$ \\
\hline Medicine/supply chain worker & 0 \\
\hline Public hospital/clinic health worker & $5[6]$ \\
\hline Private/NGO hospital/clinic health worker & $8[10]$ \\
\hline Informatics/digital health systems worker & $2[3]$ \\
\hline $\begin{array}{l}\text { Private/NGO health program manager/ } \\
\text { coordinator }\end{array}$ & $16[20]$ \\
\hline $\begin{array}{l}\text { Social worker, psychologist or health } \\
\text { communication specialist }\end{array}$ & $5[6]$ \\
\hline Health consultant & $12[15]$ \\
\hline Other & $5[6]$ \\
\hline \multicolumn{2}{|l|}{ Experience using digital health tools } \\
\hline$<6$ months & 7 [9] \\
\hline 6 months -1 year & $10[13]$ \\
\hline $1-5$ years & $22[28]$ \\
\hline $5-10$ years & $12[15]$ \\
\hline$>10$ years & $11[14]$ \\
\hline Never used digital health tools & 18 [23] \\
\hline
\end{tabular}

*, results are range [mean] for age and number [\%] for all other variables.

The five recurrent themes, ranked from the most common mentioned to the least common, were: (I) opportunities and incentives (38\%); (II) indifference (23\%); (III) role models (18\%); (IV) capacity strengthening and empowerment (15\%); (V) norms and policies (7\%).

\section{Opportunities and incentives}

About a third of the respondents' feedback (27/71) about the absence of female presenters at the conference identified a need to increase opportunities and incentives for women in the digital health field. The respondents suggested that invitations for digital health events should be sent directly to women and include incentives, such as offering awards for best female presenters. To increase opportunities, it was suggested that organizers host digital health conferences specifically for women, as described by this woman working as an official in the government health sector; "Form and organize events with women professionals who are interested in this field. I think it's [not] that they don't exist, but that they don't bave a chance."

Several respondents suggested gathering more evidence and improving the recruitment of women in digital health by using improved data bases and searches. This NGO manager suggested to; "Develop a database of women working in the digital bealth field and then invite them to upcoming events."

\section{Indifference}

There were comments from about a quarter of respondents (16/71) that suggested an attitude of indifference to the absence of female presenters at the conference. Many participants felt that the lack of female presenters was not an important issue. A male NGO manager commented that "The field is relatively new and [what is] more important than a sense of [gender] equity for now is to have the best presenters, with the most experience, beyond the issue of the sex of the presenters." Several male and female respondents also mentioned that what was most important was the quality or the capacity of the presenter, not the gender. One woman commented that, "there is still stigmatization related to the level of knowledge and capacity of women [in Bolivia], suggesting not only indifference but discrimination.

\section{Role models}

The importance of identifying female role models in the digital health field was mentioned (18\%) by many of the respondents (13/71). Role models are needed to showcase female capacity, research and accomplishments in the digital health arena, especially for the younger generation (6). Conversely when there are no female role models, it is demoralizing as exhibited by this female NGO health worker; "For me it was really very demotivating. There seemed to be no capable women. I think there are better searches to achieve a better result; it seemed like a "Fiesta Mexicana" with only macho men [at the party]." Without female role models, feelings of alienation and oppression were noted from many 
Table 2 Code structure

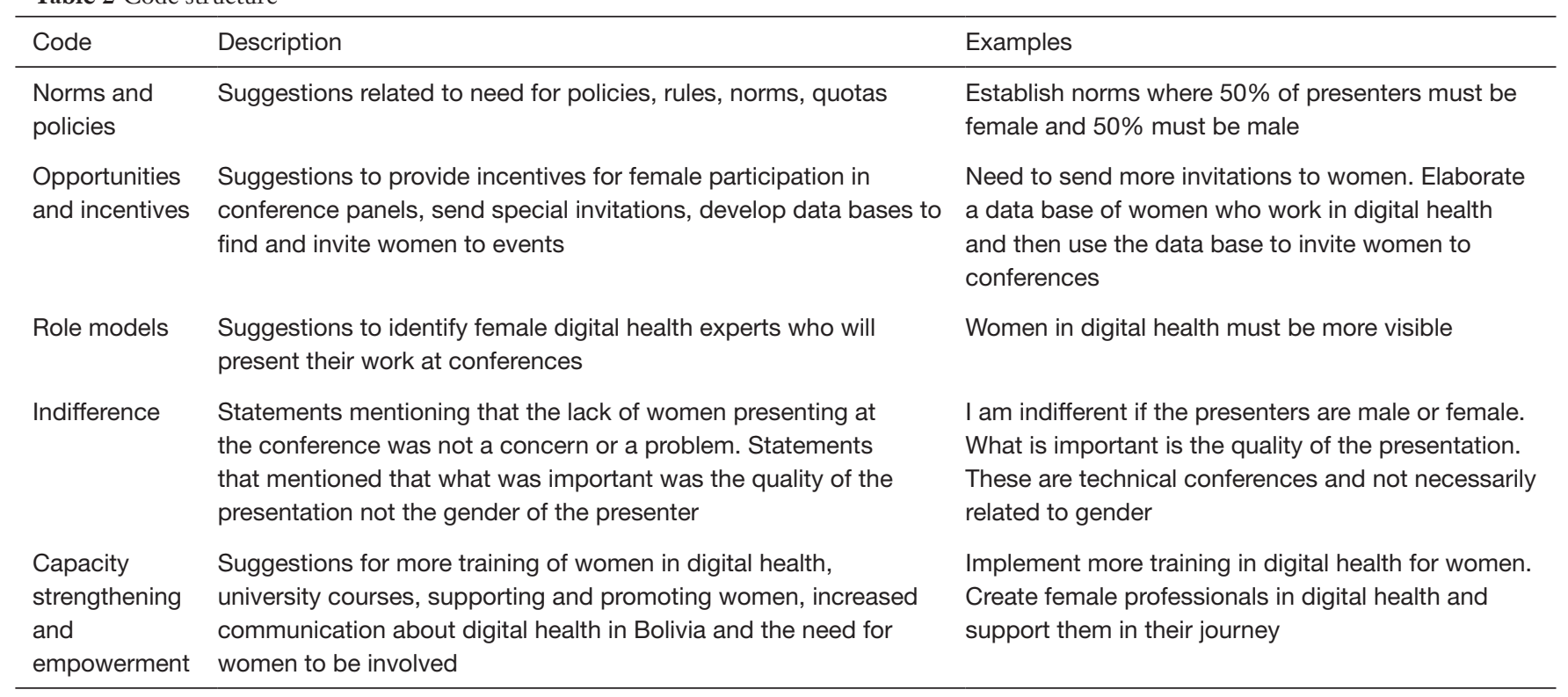

women at the conference.

\section{Capacity strengthening and empowerment}

Several of the respondents (15\%) made comments that emphasized capacity strengthening and empowerment (11/71). Suggestions for training courses for girls and women to learn knowledge and skills in the digital health field were highlighted. A female health worker recommended "developing [female] professionals and supporting them on their journey." Not only training, but ongoing support and retention of women was noted. Another female conference participant suggested that Bolivian universities focus more on human rights in their academic framework and another participant commented on the importance of "capturing and recuperating the spoken knowledge of women." The insight that women have unique knowledge and different perspectives was noted. Many of the respondents called for the socialization and diffusion on the topic of women in digital health across Bolivia. The roll out of digital health information was one of the objectives of the conference but these respondents suggest diffusion with a more in- depth focus highlighting women in the digital health field.

\section{Norms and policies}

Seven percent of the conference respondents $(5 / 71)$ suggested upstream norms and policies to address the situation of gender inequality in digital health in Bolivia. The Norms and Policies theme often overlapped with comments made in other themes, for example one participant began his feedback by saying that "gender parity should not be forced" but the overall comment was applied to the Indifference category as he went on to explain that the most important element in choosing presenters was capacity, not gender. Other respondents recommended quotas to remedy the situation and to "implement gender equity policies to for presenters and institutions." Gender quotas for academic presenters are needed for conferences and in the digital health labor workforce.

\section{Discussion}

In recent years, there has been new attention on gender disparity in speaker presentations and the resulting impact at scientific conferences (14). We conducted an in-depth qualitative analysis of participant perspectives related to the absence of female presenters at a digital health conference in Bolivia. Many conference respondents noted that the absence of women on the expert digital health panels was a major concern and recommended gender equality strategies that are consistent with themes from the literature. Respondents suggested that interventions such as providing more opportunities and incentives for women, strengthening female capacity and empowerment to work in 
digital health, identifying female role models and applying gender-transformative policies are needed to reduce gender inequality in health and technology.

A number of both male and female conference respondents stated their indifference about the lack of female presenters at the conference. Although these respondents mentioned that the absence of female presenters was not an important issue for them, there is considerable evidence that shows that the lack of female role models and mentors at conferences contributes to ongoing gender inequality (15). Gender disparity in speaker representation at scientific meetings sends a message of exclusion to women scientists (16). Many of the women at the conference felt alienated and found the absence of female presenters depressing and oppressive. Increasing the number of female presenters on scientific conference panels is important in addressing feelings of "impostor phenomenon", when women lack confidence due to their unsupportive environment (17). To change the status quo, conference organizers must be vigilant to select, invite and facilitate the participation of female speakers at scientific conferences to further gender equality in health and technology fields. A united effort from conference organizers, attendees, speakers, and male allies to tackle the gender gap in scientific panels and empower women to have their voices and innovations heard is required (18).

Following guidelines that outline selection processes for conference panels is recommended (16). There are numerous qualified females and developing extensive lists of digital health innovators and researchers to speak at conferences can help reduce gender disparity on panels. Data bases are commonly used to identify and invite experienced speakers to health conferences and a datadriven approach can enable gender balanced speaker selection for conference programs (14). Increasing female presenters at conferences will also facilitate their career and economic development through recognition of quality research, which will provide greater opportunities for collaborative outreach and the likelihood of academic promotions and leadership positions for women (14).

Empowering and Investing in female human capital will be important for national plans, policies and health systems over time (19). Women exhibit "transformational leadership qualities, including those that focus on motivating others, supporting the advance of the whole team while attending to individual needs, and creating excitement about the future, more frequently than men" (3). Motivation and team building is needed for the roll out of the new Bolivian electronic strategy and health information system to the private and public health sectors.

Developing and implementing gender-transformative policies in Bolivia's science and technology fields will promote female participation and leadership in digital health. Gender-transformative change is needed to include female ideas and talent (3). As evidenced by the success of implementing the Gender Parity in Electoral Bodies policy in Bolivia, the digital health sector should also develop and implement policies to require gender equality. There was a time when seeing and hearing women in parliament in Bolivia was unheard of, but now, six years after the law was introduced, women parliamentarians are in the majority and are actively designing innovative solutions and making decisions to support their base and country. Effective policies should be adopted to reduce gender biases and gaps in digital health in Bolivia.

When interpreting the participant perspectives and resulting themes, the limitations in our study must be considered. The question of interest was about the absence of female conference presenters, but the process to invite the presenters was not systematic. Several digital health experts, well-known in the field, recommended colleagues to present at the conference but most of them were men. Approximately one month before the conference started, the event organizers realized that only men were confirmed as speakers on the expert panels and the event organizers and research team actively tried to find and invite female presenters. In the end, only one woman agreed to present, but she cancelled at the last minute.

Another weakness was that the open-ended question was a two part question, one part asking respondents' feelings about the absence of women presenters and the other part of the question asking for suggestions to remedy the situation of gender gaps in digital health going forward in Bolivia. The respondents' themes might have been clearer if the open-ended question only asked about one issue. The open-ended question was designed to be analyzed qualitatively, thus the participant responses could not be generalized to all health workers or officials in Bolivia.

\section{Conclusions}

The results of this study can be useful for preparing a more representative digital health field in Bolivia overtime. Conference respondents provide key recommendations to reduce gender inequality at digital health conferences and in the field. More evidence is needed on gender gaps 
and gender dynamics in digital health in the Central and South American regions. More evidence is also needed from LMICs where new health technologies and health information systems are emerging. This study provides evidence from Bolivian health workers and officials on their perspectives related to the absence of female presenters at an international digital health conference and their suggestions for optimizing female participation and leadership at conferences and in the digital health field going forward.

\section{Acknowledgments}

The authors thank the Bolivia Ministry of Heath for their support with the conference and research. We also thank the Bolivian volunteers and Touro University students who assisted with the development and piloting of the research questionnaire.

Funding: This research was funded by Touro University California with support from a Robert K. Pedersen Global Outreach Grant.

\section{Footnote}

Provenance and Peer Review: This article was commissioned by the Guest Editors (Carinne Brody and Sarah Sullivan) for the series "Digital Interventions for Hard-to-reach Populations" published in mHealth. The article has undergone external peer review.

Reporting Checklist: The authors have completed the STROBE reporting checklist. Available at http://dx.doi. org/10.21037/mhealth-2019-di-12

Conflicts of Interest: All authors have completed the ICMJE uniform disclosure form (available at http://dx.doi. org/10.21037/mhealth-2019-di-12). The series "Digital Interventions for Hard-to-reach Populations" was commissioned by the editorial office without any funding or sponsorship. SS served as the unpaid Guest Editor of the series. The authors have no other conflicts of interest to declare.

Ethical Statement: The authors are accountable for all aspects of the work in ensuring that questions related to the accuracy or integrity of any part of the work are appropriately investigated and resolved. The study was conducted in accordance with the Declaration of Helsinki (as revised in 2013). The Touro University California Institutional Review Board (IRB) as well as the Universidad Mayor de San Simon Bioethics Committee approved this evaluation study. The informed consent was explained in the introduction of the questionnaire.

Open Access Statement: This is an Open Access article distributed in accordance with the Creative Commons Attribution-NonCommercial-NoDerivs 4.0 International License (CC BY-NC-ND 4.0), which permits the noncommercial replication and distribution of the article with the strict proviso that no changes or edits are made and the original work is properly cited (including links to both the formal publication through the relevant DOI and the license). See: https://creativecommons.org/licenses/by-nc-nd/4.0/.

\section{References}

1. Women and Sustainable Development Goals. Sustainable Development Knowledge Platform. Available online: https://sustainabledevelopment.un.org/index.php?page=vi ew $\&$ type $=400 \& n r=2322 \&$ menu $=35$

2. John J, Das S. State of African research: Snapshot of abstracts for the 2018 Women in Science Without Borders indaba. S Afr J Sci 2019;115:5876.

3. Delivered by women, led by men: A gender and equity analysis of the global health and social workforce. Geneva: World Health Organization; 2019 (Human Resources for Health Observer Series No. 24). License: CC BY-NC-SA 3.0 IGO. WHO.

4. Abadi M. There are only 25 women CEOs in the Fortune 500 - here's the full list. Business Insider. [citado 5 de enero de 2020]. Available online: https://www. businessinsider.com/fortune-500-companies-womenceos-2018-8

5. James J. April $6 \mathrm{~W}$ on, 2010, Pst 4:25 Pm. IT gender gap: Where are the female programmers? TechRepublic. [citado 5 de enero de 2020]. Available online: https://www. techrepublic.com/blog/software-engineer/it-gender-gapwhere-are-the-female-programmers/

6. van Staden A, Ahmed N, Getachew Y, et al. 'Gender shouldn't matter because we are all scientists here': A narration of the panel discussion at the 2nd International Women in Science Without Borders conference. South African Journal of Science 2019;115(3/4). Available online: https://www.sajs.co.za/article/view/5865

7. Bolivian Elections Result in More Women in Parliament I International IDEA. [citado 5 de enero de 2020]. Available 
online: https://www.idea.int/news-media/news/bolivianelections-result-more-women-parliament

8. Bolivia - Proportion of seats held by women in national parliaments (\%). [citado 5 de enero de 2020]. Available online: https://www.indexmundi.com/facts/bolivia/ indicator/SG.GEN.PARL.ZS

9. Mariscal J, Mayne G, Aneja U, et al. Bridging the Gender Digital Gap. Economics 2019. Available online: http://www.economics-ejournal.org/economics/ journalarticles/2019-9

10. Roberto Velazco Rivera.2018. Bolivia - LATIN AMERICA AND CARIBBEAN- P164453- Health Service Delivery Network Project - Procurement Plan (English). Washington, D.C.: World Bank Group. Available online: http://documents.worldbank.org/curated/ en/287521588609663979/Bolivia-LATIN-AMERICAAND-CARIBBEAN-P164453-Health-Service-DeliveryNetwork-Project-Procurement-Plan

11. Ricciardi W, Pita Barros P, Bourek A, et al. How to govern the digital transformation of health services. European Journal of Public Health 2019;29:7-12.

12. World Health Organization. Classification of digital health interventions v1.0: a shared language to describe the uses of digital technology for health. World Health Organization; 2018 [citado 21 de enero de 2019]. Report No.: WHO/RHR/18.06. Available online: http://apps.

doi: 10.21037/mhealth-2019-di-12

Cite this article as: Sullivan S, Posada A, Hawkins M, Higueras G. Where are the female experts? Perceptions about the absence of female presenters at a Digital Health Conference in Bolivia. mHealth 2020;6:37. who.int/iris/handle/10665/260480

13. Neves J, Lavis JN, Ranson MK. A scoping review about conference objectives and evaluative practices: how do we get more out of them? Health Res Policy Syst 2012;10:26.

14. Vallence AM, Hinder MR, Fujiyama H. Data-driven selection of conference speakers based on scientific impact to achieve gender parity. Tanner KD, editor. PLoS One 2019;14:e0220481.

15. Farr CM, Bombaci SP, Gallo T, et al. Addressing the Gender Gap in Distinguished Speakers at Professional Ecology Conferences. BioScience 2017;67:464-8.

16. Klein RS, Voskuhl R, Segal BM, et al. Speaking out about gender imbalance in invited speakers improves diversity. Nat Immunol 2017;18:475-8.

17. Stout JG. STEMing the tide: Using ingroup experts to inoculate women's self-concept in science, technology, engineering, and mathematics (STEM). J Pers Soc Psychol 2011;100:255-70.

18. Penfold R, Knight K, Al-Hadithy N, et al. Education and training Women speakers in healthcare: speaking up for balanced gender representation. Future Healthc J 2019;6:167-71.

19. Gupta N. Research to support evidence-informed decisions on optimizing gender equity in health workforce policy and planning. Hum Resour Health 2019;17:46. 